\title{
Peertechz
}

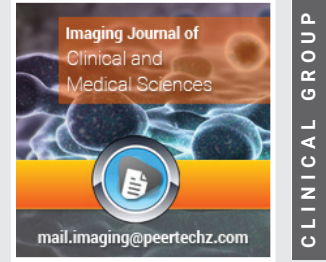

\section{Tuberculosis epidemiology in Cabo Verde from 2006 to 2016}

\author{
Silvânia Da Veiga Leal ${ }^{1 *}$, Isaías Varela² and Tomás Alves de Só \\ Valdez $^{3}$
}

${ }^{1}$ Master in Medical Parasitology, National Institute of Public Health, Assistance Disaster Square, Chã de Areia, Praia 719, Cape Verde

${ }^{2}$ Graduation in Biological Science, National Institute of Public Health, Largo do Desastre da Assistência, Chã de Areia, Praia 719, Cabo Verde

${ }^{3}$ Medical Doctor, Master in Public Health, Ministry of Health, Palácio do Governo, Praia, Cabo Verde

Received: 15 April, 2021

Accepted: 18 May, 2021

Published: 19 May, 2021

*Corresponding author: Silvânia Da Veiga Leal, Master in Medical Parasitology, National Institute of Public Health, Assistance Disaster Square, Chã de Areia, Praia 719, Cape Verde, E-mail: Silvania.Leal@insp.gov.cv Keywords: Tuberculosis; Epidemiology; Incidence; Prevalence; Cabo verde

https://www.peertechzpublications.com

\section{Check for updates}

\section{Abstract}

Tuberculosis is an infectious disease usually caused by the bacteria Mycobacterium tuberculosis. This study aimed to analyze the epidemiological profile of Tuberculosis in Cabo Verde from 2006 to 2016. This is an epidemiological, longitudinal and descriptive study in which the secondary data on Tuberculosis were obtained from the annual statistical reports of the Ministry of Health. Incidence, prevalence, mortality rate and percentage of new cases of Tuberculosis, were calculated by age group, gender and treatment for each year. During the study period, 3282 new cases of all forms of Tuberculosis were registered. The average annual incidence rate was 59 / 100,000. It was observed a higher incidence of the disease among men in the age group of 25 to 34 years old. Pulmonary Tuberculosis was the most frequent form of tuberculosis. The mortality rate in this period remained stable. Although there are positive effects from Tuberculosis control measures in the country, there is the need for complementary measures by developing active surveillance, strengthening the laboratory diagnosis capacity in order to reduce the disease prevalence and prevent multi-drug-resistant Tuberculosis. Moreover, there is a need for complementary epidemiological studies.

\section{Introduction}

Tuberculosis is an infectious disease usually caused by the bacteria Mycobacterium tuberculosis. It has existed for millennia and continues to be a major health problem worldwide. It's the ninth infectious disease that causes the most death in the world, surpassing HIV/AIDS [1,2].

It is estimated that around 1.7 billion people, $23 \%$ of the world population, have a latent infection with tuberculosis and are at risk of developing the disease during their lifetime [2].

In 2019, it was estimated that 10 million people fell ill with tuberculosis worldwide, of which 5.6 million men, 3.2 million women and 1.2 million children. Tuberculosis caused about 1.2 million deaths in HIV-negative individuals and 208000 deaths in HIV-positive individuals in 2017 [3]. Most tuberculosis cases occurred in Asia (44\%) and the African Region (25\%) and the Western Pacific (18\%), smaller proportions of cases occurred in the Eastern Mediterranean Region (8.2\%), the Europe Region (2.5\%) and the American Region (2.9\%). These regions represented $86 \%$ of the total deaths from tuberculosis in HIVnegative and HIV-positive people [1]. The HIV epidemic had a decisive impact on the magnitude of tuberculosis, increasing the number of cases in the industrialized world [4].

The global re-emergence of tuberculosis is not only related to HIV, but also to the increase in strains resistant to first line antibiotics and in particular to the emergence of multi-drugresistant strains, defined as strains simultaneously resistant to at least isoniazid (INH) and Rifampicin (RIF) [5]. Drug resistant tuberculosis poses a continuous threat worldwide. In 2017, it was estimated that 558000 people worldwide developed tuberculosis resistant to rifampicin, the most effective first line drug, and of these $82 \%$ had multi-drug-resistant tuberculosis (MDR-TB). Almost half of MDR-TB cases have been reported in India, China and the Russian Federation [2].

In Cabo Verde, on average, about 350 new cases of TB and 390 cases of HIV/AIDS are reported each year. Of the total number of notified TB cases in the country, $12 \%$ and $8.3 \%$ corresponded to TB/HIV co-infection in the years 2012 and 2013, respectively [6]. 
In 2016, the WHO estimated that the incidence of Tuberculosis in Cabo Verde was 137/100 000 inhabitants, however, the incidence rate verified in the country in that year was $42 / 100000$ inhabitants $[1,2]$. In the same year, tuberculosis' mortality rate and prevalence were $49 \%$ and $1.3 / 100000$ inhabitants, respectively.

In 1999, the WHO published an estimate that predicts an annual tuberculosis risk of $1.5 \%$ for Cabo Verde, which corresponds to an annual average of 600 to 700 new cases. However, the country has not registered occurrences of TB cases compatible with this estimate, despite the improvement of technical conditions and the adoption of protocol service for the detection of TB cases, namely the introduction of the GeneXpert MTB/RIF method. This is one of the molecular diagnostic methods that at the same time identifies the $M$. tuberculosis complex from the specific sequence of the rpoB gene in the $81 \mathrm{bp}$ region and verifies the resistance to RIF through the mutations of the gene [6-8].

The TB treatment approach in the country has been structured and decentralized over the past few decades, with a control policy at the level of primary care. First and second line drugs are available in the country for the treatment of TB. Supervised treatment is free and provided at all health facilities in the country. MDR-TB is not a major public health concern for the country. From 2011 to 2013, no case of MDR-TB was diagnosed across the country, despite cases of treatment abandonment and therapeutic failure [6].

Despite the gains obtained in the TB control, there are still some challenges for the country, namely, the implementation of culture test and the antibiotic susceptibility test, the increase in the detection rate of new cases of all form of TB and the training of health professionals with specific training on TB case management. In this sense, epidemiological investigations of the disease are important to support TB control policies and strategies.

The Tuberculosis Control activities in the country is coordinate by National Programme for the Fight against Tuberculosis and Leprosy (NPFTL), created in 1986. It is part of the National Health Directorate within the Ministry of Health. NPFTL is the national authority that records the official numbers of reported TB cases and generates the country's epidemiological and operational indicators [6].

The NPFTL has adopted since 1996 the Directly Observed Treatment (DOT) strategy, and it is responsible for the elaboration of the Technical Guide (wherein describes in detail the diagnostic methods and the treatment schemes). In 2002 was developed the first Strategic Plan for Tuberculosis Control and to date the country has elaborated three strategic Plan [6]. This study aims to analyse the epidemiological profile of tuberculosis in Cabo Verde in the 10 years period from 2006 to 2016.

\section{Material and methods}

\section{Study area}

Cabo Verde is an archipelago located $455 \mathrm{~km}$ from the west coast of Africa, in the middle of Atlantic Ocean, made by ten islands and five main islets, with 23 municipalities. In 2016 the resident population was estimated in 531,239 inhabitants. The population of Praia, the capital city of the country, and São Vicente, represented $29.2 \%$ and $15.4 \%$ of the overall population in 2016, respectively [8]. TB control activities in the country are decentralized and carried out by the Health Centers responsible for the diagnosis, treatment and follow-up of cases.

\section{Population studied}

This is an epidemiological descriptive cross sectional study, in which secondary data of new cases of tuberculosis from 2006 to 2016 were compiled and the prevalence the all forms of tuberculosis from 2006 to 2016 from the annual statistical reports of the Ministry of Health of Cabo Verde.

\section{Data collection and analysis}

The study included 3282 cases of all forms of tuberculosis recorded from 2006 to 2016, and the annual prevalence TB de 2006 to 2016 available in the respectively annual statistical reports of the Ministry of Health of Cabo Verde [8]. Information related to age group, gender, new cases of pulmonary and extra pulmonary tuberculosis, and treatment were collected for each year of the study period.

The data were recorded in an Excel spreadsheet, the incidence rate, prevalence, and mortality rate were calculated using IBM SPSS Statistics 20 (International Business Machines Corporation, New York City, NY, USA). The results were presented in graphs or tables. Due to lack of available data, incidence was calculated by years and age groups whilst prevalence was calculated only by years.

\section{Results}

During the study period, 3282 new cases of all forms of tuberculosis were recorded in Cabo Verde. The average annual incidence rate was 59/100 000 inhabitants. The lowest number of new cases (222 cases) and the lowest incidence (41.7/100 ooo inhabitants) of tuberculosis occurred in 2016. The highest incidence (79.4/100 000 inhabitants) was recorded in 2012, with a decrease in the numbers of cases from the years 2013 to 2016 (Graph 1).

During the study period, $85 \%(n=2796)$ new cases of pulmonary tuberculosis and $15 \%(n=486)$ of extra-pulmonary tuberculosis cases were recorded.

From 2006 to 2016 the average prevalence of all forms of tuberculosis in Cabo Verde was 65.7/100 000 inhabitants. The year with the highest prevalence was 2012 (83.2/100 000 inhabitants), and the year with lowest prevalence was 2016 (49/100 000 inhabitants). The prevalence curb increased from 2006 to 2012, and then a decreased consistently in the last 3 years of the study (Graph 2).

The average annual death rate, from 2006 to 2016, was 2.8/100 000 inhabitants. The highest TB mortality rate were observed in the years 2006 (4.7/100 000 inhabitants), 2011 (4.4/100 000 inhabitants), and the lowest mortality rate 


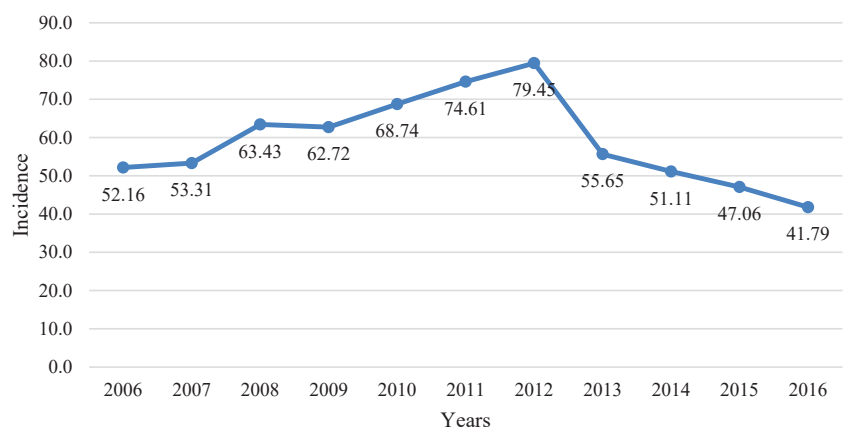

Graph 1: Incidence rate of all TB cases, per 100000 inhabitants, according to the year of occurrence in Cabo Verde, between 2006 and 2016.

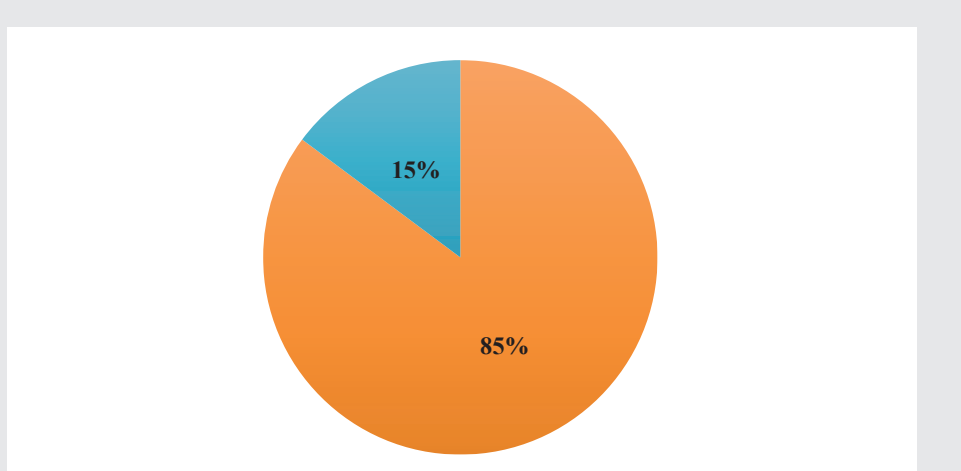

E Pulmonary Tuberculosis Extra Pulmonary Tuberculosis

Graph 2: Pulmonary and extrapulmonary proportions of tuberculosis cases.

were in the years 2008 and 2014 (both years with 1.1/100 000 inhabitants).

As for the gender regarding tuberculosis cases with positive smear microscopy, $68 \%(n=1322)$ of cases were males and $31 \%(n=599)$ were female.

Of the 1921 total new cases of tuberculosis with positive sputum smear microscopy occurred in the age groups of 2534 years old, followed by 35-44 years and from 15-24 years, representing 28.3\% $(\mathrm{n}=545), 21.3 \%(\mathrm{n}=410)$ and $20.6 \%$ $(n=396)$ of cases, respectively. The lowest number of cases occurred in the age group $0-14$ years with $1.3 \%(n=26)$ of cases. It was observed that $65.9 \%$ of TB cases with positive sputum smear microscopy were in the age group of 25-54 years old. The highest average incidence rates were observed in the age groups of 45-54 years old (67/100 000 inhabitants), followed by 25-34 years (61/100 000 inhabitants) and 35-44 years $(60 / 100000$ inhabitants), representing $11.3 \%(n=315)$, $19.5 \%(\mathrm{n}=545)$ and $14.7 \%(\mathrm{n}=410)$ of the cases analyzed in that period, respectively. The lowest average incidence rate was in the age group 0-14 years (1/100 000 inhabitants), which represented $0.93 \%(n=26)$ of the cases in the studied period (Table 1).

The incidence of TB by islands in Cabo Verde show that a higher incidence rate was observed in the islands of São Nicolau (72.6/10obooo inhabitants), followed by São Vicente (66.5/100 000 inhabitants) and Maio (56.3/100 000 inhabitants). The island with the lowest rate was Boa Vista (17.1/100 000 inhabitants).
Concerning the treatment of pulmonary tuberculosis cases with positive smear microscopy, it was not possible to analyze the data from the years 2007 and 2016, because these are not available in the respective annual statistical reports. From the available data, it was observed that $54 \%$ were cured, $8 \%$ drop out treatment, $0.5 \%$ were considered therapeutic failure. The average $54 \%$ cured is below the $85 \%$ target set by the WHO. The treatment drop-out rate has decreased, but it's still above the $5 \%$ WHO target, and the rate of therapeutic failure has decreased over the years from $2.4 \%$ to $0.5 \%$.

\section{Discussion}

TB can affect anyone anywhere, but most people who develop the disease are adults, but this disease is curable and preventable.

The results of this work showed that during the study period men were the most affected by tuberculosis. The high percentage of TB cases among men is found in several studies and worldwide the male-female ratio was 1.7. This percentage may be associated with cultural, social and economic factors related to gender. Men tend to have greater exposure to risk factors and they less seek for health services. To address that, the program must develop more specific actions to reach this population with high incidence of the disease, namely, a broader dissemination of information on the prevention of the disease.

Analysing the data, it was observed that from 2006 to 2016, $65.9 \%$ of the TB cases with positive smear was in the age group of 25 to 54 years old. As this is an economically active age group of individuals and prone to more mobility, the active search for clinically suspect cases in this age group is essential for the early identification and treatment of infections, thus seeking to interrupt the chain of transmission [14].

Comparing the average incidence of this study with the previous decade 1995 to 2005 (average incidence 52.7/100 ooo inhabitants) [6], there was an increase in incidence. This increase might be associated with the measures and strategies implemented, namely, the introduction of the GeneXpert MTB/ RIF method, which is a fast, sensitive and specific molecular method for tuberculosis diagnosis, allowing the detection of positive cases not detected by bacilli smear microscopy [10-12].

The prevalence of tuberculosis during the study period increased until 2012 and from that period onwards, there was a decrease until 2016. This decrease may be associated with a low infection rate in the country, interventions such as free and supervised treatment, active case management and the implementation of the use of a rapid molecular diagnostic method (Xpert ${ }^{\circledR}$ MTB / RIF) [6].

The low detection of extrapulmonary TB may be associated with limited laboratory resources to diagnose the extrapulmonary form and/or unfamiliarity of health professionals with extrapulmonary TB cases. The statistical reports analyzed do not contain information on the anatomical location of extrapulmonary TB cases. These results are similar to other studies, which demonstrates the importance of an 
Table 1: Incidence rate of all new cases of tuberculosis per 100000 inhabitants, by age group and year of occurrence in Cabo Verde, between 2006 and 2016.

\begin{tabular}{|c|c|c|c|c|c|c|c|c|c|c|c|c|c|c|c|c|c|c|c|c|c|}
\hline \multirow{3}{*}{ Years } & \multicolumn{7}{|c|}{ Population } & \multicolumn{7}{|c|}{ New cases } & \multicolumn{7}{|c|}{ Incidence rate } \\
\hline & \multicolumn{7}{|c|}{ Age groups } & \multicolumn{7}{|c|}{ Age groups } & \multicolumn{7}{|c|}{ Age groups } \\
\hline & $0-14$ & $15-24$ & $25-34$ & $35-44$ & 45-54 & $55-64$ & $>65$ & $0-14$ & $15-24$ & $25-34$ & $35-44$ & $45-54$ & $55-64$ & $>65$ & $0-14$ & $15-24$ & $25-34$ & $35-44$ & $45-54$ & 55-64 & $>65$ \\
\hline 2006 & 169185 & 105627 & 65828 & 65828 & 32933 & 13675 & 31201 & 4 & 29 & 38 & 23 & 14 & 10 & 13 & 2 & 27 & 58 & 35 & 43 & 73 & 42 \\
\hline 2007 & 166918 & 107925 & 68701 & 68701 & 35019 & 14830 & 30635 & 0 & 40 & 51 & 31 & 19 & 7 & 12 & 0 & 37 & 74 & 45 & 54 & 47 & 39 \\
\hline 2008 & 164496 & 109765 & 71827 & 71827 & 37493 & 15788 & 30160 & 3 & 42 & 51 & 39 & 30 & 17 & 9 & 2 & 38 & 71 & 54 & 80 & 108 & 30 \\
\hline 2009 & 161567 & 110981 & 75698 & 75698 & 39748 & 16682 & 30049 & 5 & 40 & 50 & 39 & 33 & 6 & 11 & 3 & 36 & 66 & 52 & 83 & 36 & 37 \\
\hline 2010 & 158555 & 111885 & 79355 & 54561 & 41736 & 17853 & 30094 & 2 & 42 & 46 & 39 & 39 & 12 & 12 & 1 & 38 & 58 & 71 & 93 & 67 & 40 \\
\hline 2011 & 156820 & 111668 & 82981 & 55864 & 43305 & 19379 & 29913 & 4 & 31 & 58 & 39 & 37 & 6 & 7 & 3 & 28 & 70 & 70 & 85 & 31 & 23 \\
\hline 2012 & 155698 & 110649 & 86578 & 57085 & 45294 & 21197 & 29482 & 0 & 48 & 49 & 43 & 32 & 11 & 6 & 0 & 43 & 57 & 75 & 71 & 52 & 20 \\
\hline 2013 & 154862 & 109283 & 90142 & 58586 & 46904 & 23443 & 28953 & 2 & 35 & 56 & 39 & 23 & 15 & 12 & 1 & 32 & 62 & 67 & 49 & 64 & 41 \\
\hline 2014 & 154415 & 107220 & 93870 & 60560 & 48160 & 25829 & 28412 & 3 & 25 & 67 & 28 & 27 & 8 & 11 & 2 & 23 & 71 & 46 & 56 & 31 & 39 \\
\hline 2015 & 154232 & 104771 & 97494 & 62684 & 48645 & 28410 & 28596 & 3 & 36 & 33 & 53 & 29 & 7 & 9 & 2 & 34 & 34 & 85 & 60 & 25 & 31 \\
\hline 2016 & 153975 & 102475 & 100676 & 65427 & 49772 & 29857 & 29057 & 0 & 28 & 46 & 37 & 32 & 23 & 5 & 0 & 27 & 46 & 57 & 64 & 77 & 17 \\
\hline Average & 159157 & 108386 & 83014 & 63347 & 42637 & 20631 & 29687 & 2 & 36 & 50 & 37 & 29 & 11 & 10 & 1 & 33 & 61 & 60 & 67 & 56 & 33 \\
\hline
\end{tabular}

early and correct diagnosis of the pulmonary form, which allow the implementation of prevention and control transmission measures. Besides being more frequent, pulmonary TB is also the most pertinent for public health, as it is responsible for the spread of the disease, hence the importance of the diagnosis based on sputum smear microscopy for early detection, confirmation and adequate case management. However, there may be a need for other complementary diagnosis besides sputum smear microscopy and clinical investigation of cases, considering that sputum smear microscopy presents variable sensitivity, especially in situations of paucibacillary tuberculosis, namely, in cases of TB/HIV co-infection, children, extrapulmonary TB, which can result in false negatives, also it does not allow for distinction between $M$. tuberculosis and nontuberculous mycobacteria [13-16].

In 2016 the WHO estimated the mortality rate for Cabo Verde, including HIV-infected patients, at 9.7/100 000 inhabitants, however the observed rate for that year was 1.3/100 000 inhabitants. It should be noted that statistical reports do not provide data on TB/HIV co-infection. Overall, the mortality rate from pulmonary TB decreased from 2006 to 2016 with a slightly increase in 2015. Despite this increase, the mortality rate remained stable, varying from 3 to 4 deaths per 100000 inhabitants (Graphs 3,4).

The failure to reach the percentage of cure and the treatment abandonment set by the WHO, may be due to the mobility of patients between the islands, the lack of means and strategies for seeking patients who abandon treatment, the stigma of the disease, the long treatment period and the weak community involvement in controlling the disease.

During the study period, there was an absence of some data, namely, age, sex in some years, which did not allow for a more complete profile of the disease.

\section{Conclusion}

Tuberculosis is one of the oldest diseases affecting humanity and constitutes a serious public health problem worldwide. The average annual TB incidence rate was 59/100 000 inhabitants from 2006 to 2016 in Cabo Verde. The most common clinical form is the pulmonary TB. Male individuals were the most affected by the disease (54\%), and the most affected age group

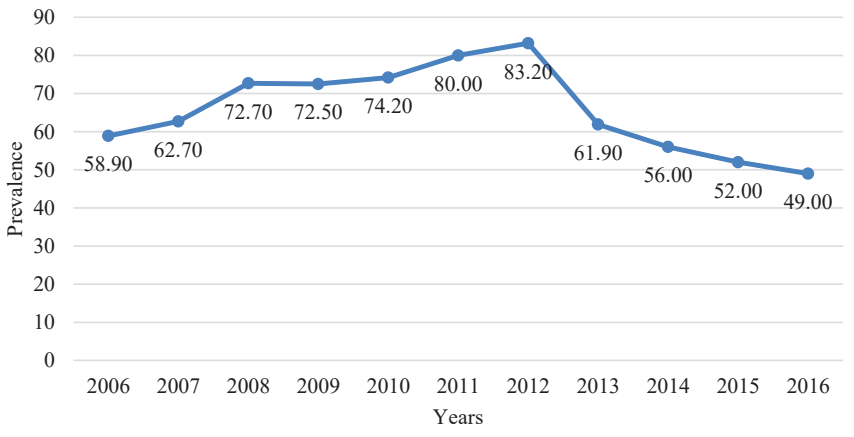

Graph 3: Prevalence rate of all cases of tuberculosis between 2006 and 2016 in Cabo Verde.

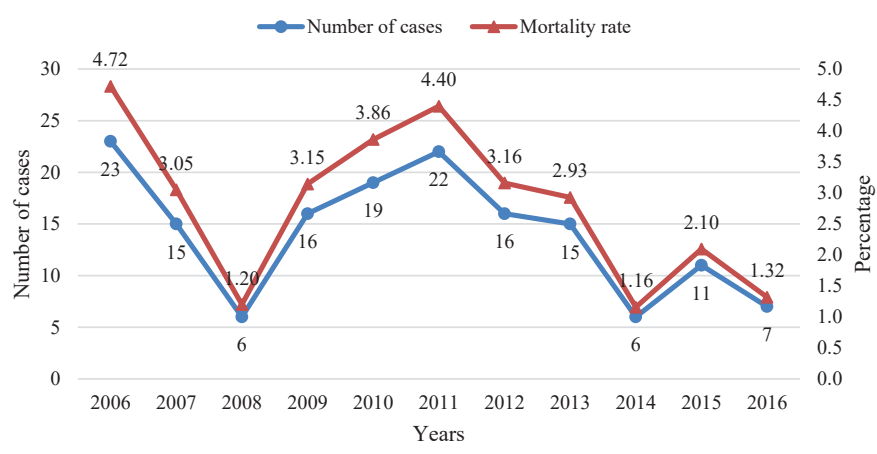

Graph 4: Total number of deaths and mortality rates due to TB in Cabo Verde between 2006 and 2016 .

corresponds to the economically active individuals. Therefore, improving the capability of health services to actively search for suspected cases and strengthening the diagnosis capacity and response, namely the treatment of the population at greatest risk, is likely the strategy that must be promoted and implemented.

Due to the variable sensitivity of sputum smear microscopy, the use of other forms of diagnosis, namely molecular methods that offer greater sensitivity and specificity for early detection and the ability to detect mixed infections, are important for the control and treatment of the disease.

The percentage of cured cases and treatment abandonment have decreased, but have not yet reached the goals defined by 
WHO. However, strategies and measures must be reinforced to reduce the spread of the disease in the community and avoid the emergence of resistance to antibiotics used in therapeutic.

It was observed the absence of systematic statistical data analysis by year, namely, the age group and the treatment, which represented a limitation of this study. The improvement in the cases notification and the standardization of information are important for determining the complete disease profile.

There is a need to conduct complementary epidemiological studies of tuberculosis in Cabo Verde with information on the profile of the affected population, laboratory results, treatment results, drug resistance and other relevant information on the disease determinants in the country, in order to better assess the real situation of the disease in the country and contribute with evidence to subsidize the policy and strategies for the TB control in Cabo Verde.

\section{Acknowledgement}

Dr. Domingos Veiga Varela, for providing statistical reports.

\section{Ethical considerations}

The data came from the Ministry of Health's statistical reports and are available on the Ministry's website for public consultation. Therefore, this study does not involve direct participation of individuals and the analysis of public data does not require ethical approval.

\section{References}

1. World Health Organization (2016) Global Tuberculosis Report. France: World Health Organization. Link: https://bit.ly/2T2Po8Z

2. World Health Organization (2018) Global Tuberculosis Report. France: World Health Organization. Link: https://bit.ly/33P515Y

3. World Health Organization (2019) Global tuberculosis report executive summary. Geneva: World Health Organization. Link: https://bit.ly/3tVzzgZ

4. Kasper D, Eugene B, Anthony F, Stephen H, et al. (2006) Harrison Manual de Medicina (16 ed.). (McGraw-Hill, Ed.) Madrid.

5. World Health Organization (2008) Anti-tuberculosis drug resistance in the world. Fourth global report - 2002-2007. Genebra. Link: https://bit.ly/3bywgpJ

6. Ministério da Saúde, Programa Nacional de Luta Contra a Tuberculose e Lepra (2014) Plano Estratégico Nacional de luta contra a Tuberculose, 2015-2019. Praia, Cabo Verde.

7. Patel VB, Theron G, Lenders L, Matinyena B, Connolly C, et al. (2013) Diagnostic accuracy of quantitative PCR (Xpert MTB/RIF) for tuberculous meningitis in a high burden setting: a prospective study. PLoS Med 10: e1001536. Link: https://bit.ly/3wjFu0Z

8. Marlowe EM, Novak-Weekley SM, Cumpio J, Sharp SE, Momeny MA, et al (2011) Evaluation of the cepheid Xpert MTB/RIF assay for direct detection of Mycobacterium tuberculosis complex in respiratory specimens. J Clin Microbiol 49: 1621-1623. Link: https://bit.ly/3v9S8PG

9. Iram S, Zeenat A, Hussain S, Yusuf NW, Aslam M (2015) Rapid diagnosis of tuberculosis using Xpert MTB/ RIF assay - Report from a developing country Pak J Med Sci 31: 105-110. Link: https://bit.ly/3yf5EUt

10. Instituto Nacional de Estatistica (2017) Anuário Estatístico Cabo Verde 2016 Praia, Cabo Verde.

11. Patil N, Saba H, Marco A, Samant R, Mukasa L (2014) Initial experience with GeneXpert MTB/RIF assay in the Arkansas Tuberculosis Control Program. Australas Med J 7: 203-207. Link: https://bit.ly/2RrCwZp

12. Steingart KR, Schiller I, Horne DJ, Pai M, Boehme CC, et al. (2014) Xpert® MTB/ RIF assay for pulmonary tuberculosis and rifampicin resistance in adults. Cochrane Database Syst Rev 21: CD009593. Link: https://bit.ly/3fvsIFX

13. Moure R, Muñoz L, Torres M, Santin M, Martín R, et al. (2011) Rapid detection of Mycobacterium tuberculosis complex and rifampin resistance in smearnegative clinical samples by use of an integrated real-time PCR method. J Clin Microbiol 49: 1137-1139. Link: https://bit.ly/3fmepTU

14. Parsons L, Somoskövi A, Gutierrez C, Lee E, Paramasivan C, et al. (2011) Laboratory diagnosis of tuberculosis in resource- poor countries: challenges and opportunities. Clin Microbiol Rev 24:314-350. Link: https://bit.ly/3bBhBtH

15. World Health Organization (1993) Treatment of tuberculosis: guidelines for national programmes: World. (W. H. Organization, Ed.).

16. Ministério da Saúde e da Segurança Social (2017) Relatórios Estatísticos 2006 a 2016. Link: https://bit.ly/2T0moyw

Discover a bigger Impact and Visibility of your article publication with Peertechz Publications

Highlights

* Signatory publisher of ORCID

* Signatory Publisher of DORA (San Francisco Declaration on Research Assessment)

* Articles archived in worlds' renowned service providers such as Portico, CNKI, AGRIS TDNet, Base (Bielefeld University Library), CrossRef, Scilit, J-Gate etc.

* Journals indexed in ICMJE, SHERPA/ROMEO, Google Scholar etc

* OAl-PMH (Open Archives Initiative Protocol for Metadata Harvesting)

* Dedicated Editorial Board for every journal

* Accurate and rapid peer-review process

* Increased citations of published articles through promotions

* Reduced timeline for article publication

Submit your articles and experience a new surge in publication services (https://www.peertechz.com/submission).

Peertechz journals wishes everlasting success in your every endeavours.

Copyright: @ 2021 Veiga Leal SD, et al. This is an open-access article distributed under the terms of the Creative Commons Attribution License, which permits unrestricted use, distribution, and reproduction in any medium, provided the original author and source are credited. 